\title{
The Study of Climate Change, Using Statistical Analyses (Case Study: Precipitation Variation in Zabol, Iran)
}

\author{
Amir Gandomkar
}

\begin{abstract}
The formation of settlement mainly depends on the climatic conditions of that region. And when people can adapt themselves and their activities with the climate of a region, communities appear. Precipitation is the most important climatic parameter in determining the climate kind in an area.

Generally, we use long term annual and monthly precipitation to show rainfall in a region. Whenever there is little precipitation, the residents adapt themselves with this shortage. But if there is a lot of precipitation change in a region and precipitations distribution is too much and also unpredictable, the human life will be in danger. Precipitation change in the long term is of great important, but more important than that is the change in precipitation coefficient variation.

An analysis of precipitation statistics an Zabol station shows that mean annual precipitation in Zabol has been about 61 millimeters over the last forty years, with the lowest in 2001 (7.2 $\mathrm{mm})$ and the highest in $2005(129.5 \mathrm{~mm})$. The amount of precipitation has fluctuations during this time with no definite rise or fall, but precipitation coefficient variation during these years has increased compared with that of the previous decades. If this trend continues, it can cause many problems for the residents in this region.
\end{abstract}

Index Terms-Precipitation Variation, Coefficient Variation, NAO, ENSO

\section{INTRODUCTION}

Change of the rate of rains among the considerable points of climatic changes increasing or decreasing the rain effects many other climatic phenomena and environmental factors such as flowing water, flood water, weather temperature, humidity and also many human activities such as farming, type of houses, etc.

Razi'ee [1] considered the trend of changing the rate of raining, in an article entitled "the analysis of the trend of annual raining in dry and semi-dry lands in the center and east of Iran", in 79 stations of these regions by using non-parametric tests and concluded that there is no change of climate in these regions, although some of the stations showed increase and some others indicated reduction in raining, but there were no changes in most of the stations.

Banivahid and Alijani [2] considered the dry and wet years and the foreseeing of climatic change in the region of Birjand, and by using monthly mount of rain and Birjand temperature in the period of 1995-2000 and applying multivariable statistical methods, revealed the temperature and

Manuscript received January 13, 2001.

Dr Amir Gandomkar, Professor assistant of Najafabad Branch, Islamic Azad University, Najafabd, Iran

Phone:+989133254097; e-mail: aagandomkar@yahoo.com raining situations in Birjand station.

With an article titled "Time and place changes of rain in Iran", Asakereh [3] has considered the climatic change regarding rain in different places and times, by using the statistics for raining in 152 synoptic and 170 climatology stations during the period of 1961-2003.

Germer [4] considered the monthly changes of rain, food, dryness and flowing water around the vicinity of Yong Tes River in China. He considered that the flowing of water was increasing in the upper part of the region and the famine phenomenon was increasing in the middle part of the region.

Gong [5] considered the daily changes of rain in the semi-dry area of North China. The study was for the period between 1956 and 2000 and concluded that the rate of raining was decreasing and the number of rainy days reduced by 8 days in that region.

Tabri and others [6] by Analysis of long-term climatic datasets is currently of unprecedented interest to the scientific community. In this study, the trends of the annual maximum (Tmax), minimum (Tmin) and mean (Tmean) air temperatures and precipitation $(\mathrm{P})$ time series were examined in the west, south and southwest of Iran for the period 1966-2005. The magnitude of the climatic trends was derived from the slopes of the regression lines, and the statistical significance was determined by means of the Mann-Kendall, Mann-Whitney and Mann-Kendall rank statistic tests. Pre-whitening was used to eliminate the influence of serial correlation on the Mann-Kendall test. The results showed a warming trend in annual Tmean, Tmax and Tmin at the majority of the stations which mostly began in the 1970s. On average, the magnitudes of the significant positive trends in annual Tmean, Tmax and Tmin were $(+) 0.412,(+) 0.452$ and $(+) 0.493^{\circ} \mathrm{C}$ per decade, respectively. However, the variations of the $\mathrm{P}$ series were not uniform over the region and there were various patterns (increasing and decreasing trends).

Kousari and others [7] show that a significant decrease in the precipitation was seen in summer in different stations. Most of the eastern and centrally located stations showed a decrease in relative humidity trend, while this condition was not recorded in Zagros and northern part of Iran. The present results also showed that the upward trend of minimum air temperature had an effect in increasing the mean air temperature in the stations with temperature ascending trend. This effect of minimum temperature was significantly more than that of the maximum temperature, which could be the result of increasing the amount of greenhouse gases and the reflection of received thermal energies, from land through the night. This increase in the temperature and a decrease in relative humidity would cause an increase in the evaporation of the received precipitation. 
Tabari and others [8] show that Annual analysis of the ETo series indicated a positive trend in $70 \%$ of the stations according to the Mann-Kendall test and the Sen's slope estimator and in $75 \%$ of the stations according to the linear regression. The magnitude of significant positive trends in annual ETo varied from $(+) 11.28$ to $(+) 2.30 \mathrm{~mm} /$ year. On the seasonal scale, stronger increasing trends were identified in ETo data in winter and summer compared with those in autumn and spring. Meanwhile, the highest numbers of stations with significant trends were found in the monthly ETo series in February, while the lowest numbers of stations with significant trends were observed in November. Analysis of the impact of climatic variables on the significant increasing trend in ETo showed that the increasing trend was mainly caused by a significant increase in air temperature during the study period.

Tabari. H and Talaee. P.H [9] show that The magnitude of the significant negative trends in annual precipitation varied from (-)1.999. mm/year at Zanjan station to (-)4.261. $\mathrm{mm} /$ year at Sanandaj station. The spatial distribution of the annual precipitation trends showed that the significant negative trends occurred mostly in the northwest of Iran. On the seasonal scale, the trends in the spring and winter precipitations time series were mostly negative. The highest numbers of stations with significant trends occurred in winter while no significant positive or negative trends were detected by the trend tests in autumn precipitation. The significant negative trends ranged between (-)0.283. mm/year at Zahedan station and (-)0.807. mm/year at Sanandaj station in winter season. In addition, the highest and lowest significant increases of precipitation values were obtained over Semnan and Mashhad in summer at the rates of $(+) 0.110$. mm/year and $(+) 0.036$. mm/year, respectively.

It has been tried in this research to define the changes of the amount of rain in Zabol station for the period 1963-2005 and consider the trend of rain in this region. It has also attempted to find whether the rain had a definite trend in this station or not, and what the situation will be, regarding raining in future, in this region.

\section{Methodology}

The monthly data of the synoptic Zabol station for 1963-2005 was used to analyze the rate of change of raining in Zabol station. To reveal the change of raining in this station, the descriptive and surveying methods and also the multi-variable statistical method were used. Linear regression and determining the change of rain by timely raining have been employed in this research together with analysis of the average, standard deviation and variability coefficient indexes and also the graphs of different climates.

\section{RESULTS AND DISCUSSION}

Zabol station is situated in Sistan and Baluchestan province in the east of Iran. [10] The attitude of this station is $489 \mathrm{~mm}$ above sea level. Consideration of long term statistics for monthly and annual amount of rain of this station between 1963-2005 shows that the average annual rain in this station is about $61.3 \mathrm{~mm}$. the highest rates belong to the months of March, January and February with $15.6 \mathrm{~mm}, 14.4 \mathrm{~mm}$ and $13.9 \mathrm{~mm}$ respectively and the non-raining periods of June, July, August, and September had the lowest average of monthly rain. (Figure 1)

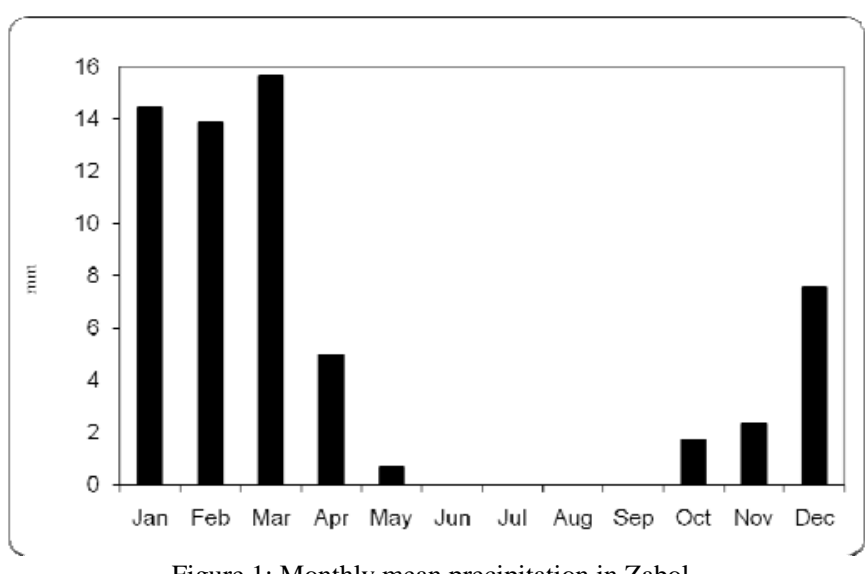

Figure 1: Monthly mean precipitation in Zabol

Considering the annual rain in Zabol station shows that the highest amount of rain belonged to 2005 with $129.5 \mathrm{~mm}$ and the lowest amount belonged to 2001 with $7.2 \mathrm{~mm}$. (Figure 2)

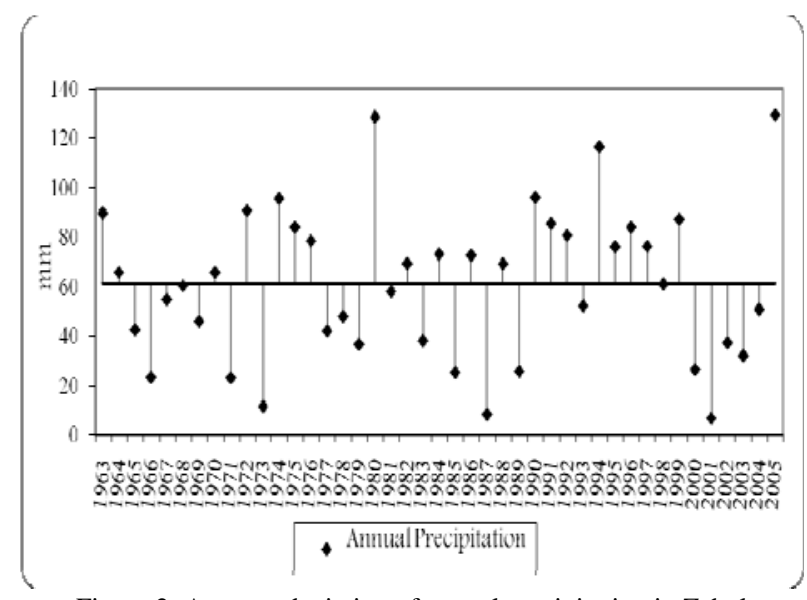

Figure 2: Average deviation of annual precipitation in Zabol

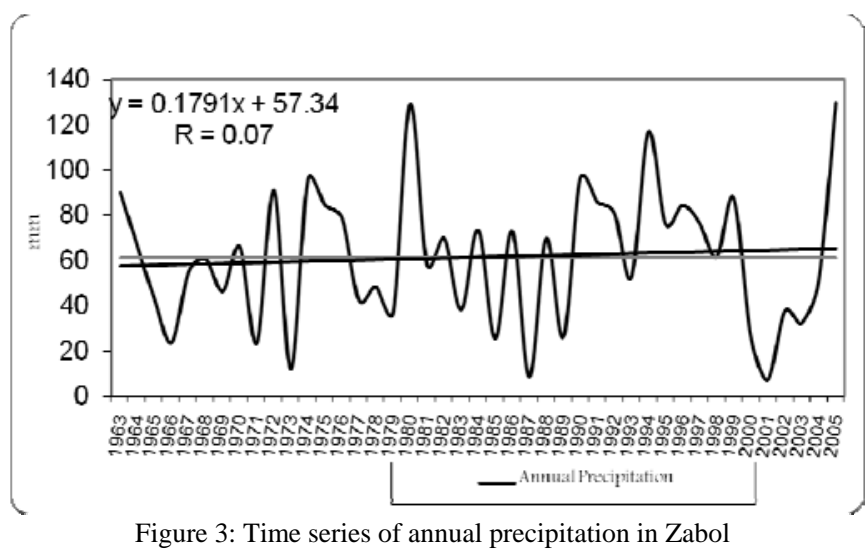

As a whole, considering the trend of annual change of the rate of rain to Zabol station indicates that the change in the amount of rain in this station between 1963 and 2005 was not considerable. Analyzing the change in the amount of rain in this station indicates that the rate of rain in the recent years has an increase and the standard deviation for the raining also increased as compared to the previous years. To reveal this 
fact, the variation for the coefficient of variability (CV) for the raining was calculated for Zabol station and the relevant graph was drawn. (Figure 5)

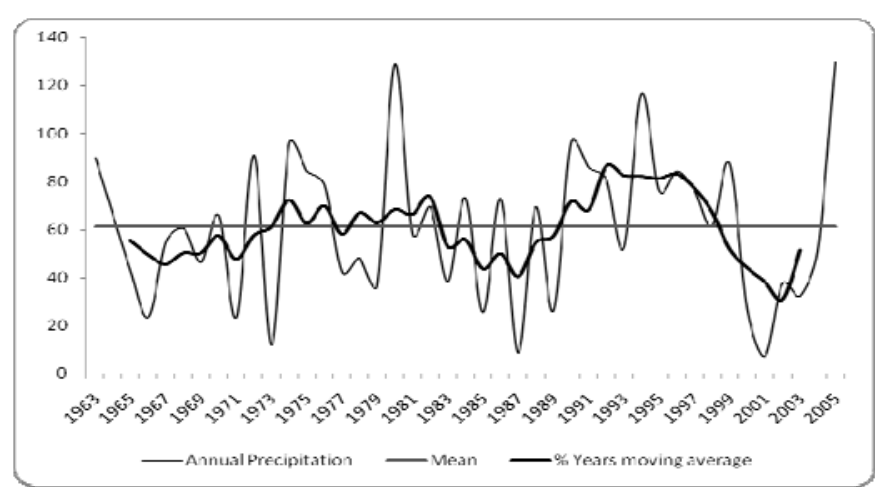

Figure 4: 5 years moving average of annual precipitation in Zabol

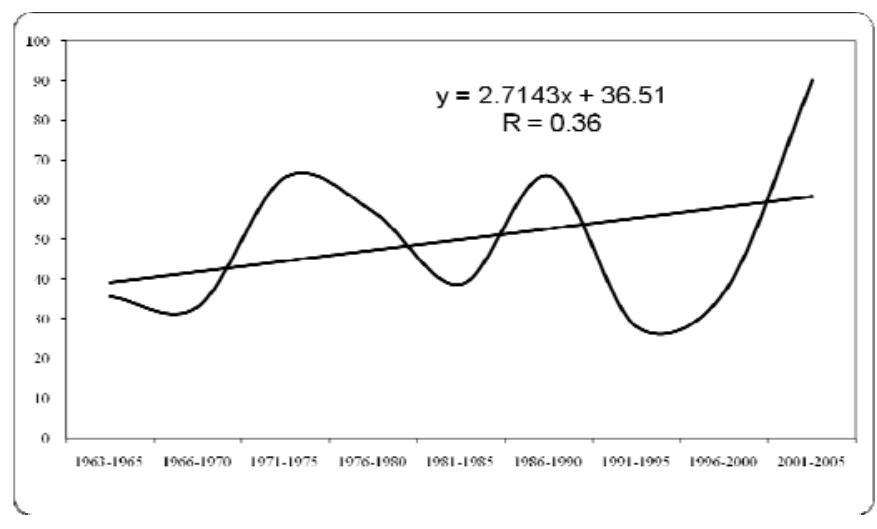

Figure 5: Coefficient variation (CV) of annual precipitation in ZAbol

As it is defined in this graph, the variability of the trend of raining has increased in this station in the past years and consideration of the coefficient of correlation shows that this change was significant, taking into consideration the possibility of error rate of 0.10 , and in fact the stability of raining in Zabol station has decreased and the intensity for the famine and also wet years has increased. Continuation of this trend shows a lower stable situation for the climate in future in this region and as a result the plant coverage will be with lower stability affected by the climate in this area.

Analysis of the relation of raining in Zabol station with remote relations (such as ENSO and NAO) shows that there is only one significant relation between the amount of annual rain in Zabol and the positive phase of NAO. Hence, increasing NAO index, the amount of rain in Zabol could also increase.

\section{CONCLUSION}

The rate of rain in Zabol has increased a little in the past years, but the increase was not significant. But analyzing the coefficient of variability for the raining shows that the stability of the rain in this period in this station had a significant decrease and the intensity of famine and wet years has increased. Raining out of the average amount and fluctuations of the amount of rain is one of the characteristics of dry lands and if the increasing trend of the CV for the raining continues in Zabol, it will indicate that the region is on the point of a small climate change and the famine is increasing. This should be considered in future plantings and programs and the limitations and opportunities of this phenomenon should be identified and evaluated.

\section{REFERENCES}

[1] T. Raziee, "The analysis of the trend of annual raining in dry and semi-dry lands in the center and east of Iran,” Isfahan Water Journal, Volume 54, December 2005, pp. 25-32.

[2] A. Banivaheb and B. Alijani, "Climate change prediction in Birjand," Geographic research, Volume 52, September 2005, pp. 95-104.

[3] H. Asakere, "Temporal and local precipitation changes in Iran," Geography and development, Volume 10, March 2011, pp. 85-97.

[4] M. Germer, " Seasonal precipitation changes in the wet season and their influence on flood/drought hazards in the Yangtze River Basin, China,” Quaternary International, Volume 186, Issue 1, August 2008, pp. 12-21.

[5] D. Gong, "Daily precipitation changes in the semi-arid region over northern China," Journal of Arid Environments, Volume 59, Issue 4, December 2004, pp. 771-784.

[6] H. Tabari, B.S. Somee and M.R. Zadeh, "Testing for long-term trends in climatic variables in Iran,” Atmospheric Research, Volume 100, Issue 1, April 2011, pp. 132-140.

[7] M.R. Kousari and others, "An investigation of the Iranian climatic changes by considering the precipitation, temperature, and relative humidity parameters,” Theoretical and Applied Climatology Volume 103, Issue 3-4, March 2011, pp. 321-335.

[8] H. Tabari and others, "Trend analysis of reference evapotranspiration in the western half of Iran,” Agricultural and Forest Meteorology Volume 151, Issue 2, February 2011, pp. 128-136.

[9] Tabari. H and Talaee. P.H, "Temporal variability of precipitation over Iran: 1966-2005,” Journal of Hydrology, Volume 396, Issue 3-4, January 2011, pp. 313-320.

[10] M, Kaviani and B, Alijani, Applied Climatology. Samt Publisher, 1993, p.254.

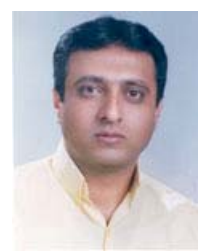

Dr Amir Gandomkar. Born place: Isfahan, Iran Born Date: 04-04-1972

Phd in Climatology, research in Applied climatology, Environment, Climate change and Renewable Energy. Faculty member of Islamic Azad University - Najafabad Branch. 